\title{
Pronoun interpretation in Italian: assessing the effects of prosody
}

\author{
Heather Goad ${ }^{1}$, Lydia White¹, Guilherme D. Garcia² ${ }^{2}$ Natália Brambatti Guzzo ${ }^{1}$, Marzieh Mortazavinia ${ }^{1}$, Liz Smeets ${ }^{1} \&$ \\ Jiajia $\mathrm{Su}^{3}$ \\ ${ }^{1}$ Department of Linguistics, McGill University, ${ }^{2}$ Department of English, Ball State University, \\ ${ }^{3}$ National Research Centre for Foreign Language Education, Beijing Foreign Studies University
}

Introduction. In this paper, we offer a prosodic account to supplement some well-known findings relating to choice of antecedents for pronouns in Italian. We argue that methodologies previously used to assess pronoun interpretation are flawed in that they rely only on written language to assess interpretation. In biclausal sentences like (1a), null pronouns are preferred when the antecedent is the discourse topic and subject of a higher clause; otherwise, overt pronouns are preferred. Sorace and Filiaci (2006) and Belletti et al. (2007) report that second language (L2) speakers of Italian overuse overt pronouns in contexts where null pronouns would be appropriate; they attribute this overuse to problems at the syntax-discourse interface (a failure to fully appreciate the discourse requirements on overt pronouns) and/or to processing problems relating to the Position of Antecedent Strategy (PAS) proposed by Carminati (2002). In addition to the behaviour of the L2ers with respect to overt pronouns, there are some puzzling results in this literature: both native speakers and L2ers fail to perform as expected with null pronouns, allowing them to take object antecedents about $50 \%$ of the time.

Hypothesis: We hypothesize that prosody influences pronoun choice, leading to interpretations other than those expected if only syntax-discourse considerations are involved. We expect interpretive differences depending on whether or not there is a pause between the clauses containing the pronoun and its antecedent and whether or not an overt pronoun is contrastively stressed. In previous literature, picture verification tasks were used: participants made judgments based on pictures accompanied by orthographically-presented sentences, making it impossible to determine what (silent) prosody the participants were assuming.

Method: In this paper, we report on an experiment testing effects of pause and stress on pronoun interpretation. Participants were native speakers of Italian and high-intermediate/advanced L2 learners of Italian with Dutch and English as L1s. To test for prosodic effects, it is essential that participants hear the stimuli rather than read them. 80 biclausal sentences were presented aurally only; see (1a). Each sentence was followed by an aural comment about the potential antecedent (subject, object, external), which participants had to agree or disagree with; see (1b). Overt/null pronouns, presence/absence of pause and presence/absence of contrastive stress on overt pronouns were manipulated.

Results: Results show that pause and stress affected participants' antecedent choices. When there was no pause between clauses, we find a strong preference for subject antecedents for null pronouns (see leftmost red panel in Figure 1). With no pause between clauses and no contrastive stress on overt pronouns, we find a strong preference for object antecedents; see upper left green panel in Figure 2. These results are consistent with - but more definitive than - those reported in the previous literature.

The following results support our hypothesis that prosody leads to responses that depart from these preferences:

- Both groups show increased choice of object antecedents for null pronouns when the clauses are separated by a pause (see green panels in Figure 1). We propose that a pause permits an analysis where the subordinate clause has been extraposed such that Spec IP is no longer necessarily 'close' enough to allow for the subject as antecedent.

- L2ers show reduced acceptance of subject antecedents to unstressed overt pronouns when there is a pause (see upper red panels in Figure 2), suggesting that overuse of overt pronouns might reflect insertion of a pause in silent reading of stimuli in earlier studies.

- Contrastive stress on overt pronouns reduced L2ers' acceptance of object antecedents (see green panels in Figure 2) and increased their acceptance of external referents (see lower blue panels in Figure 2). We propose that when the pronoun bears contrastive stress, this signals a contrast with the object, thus favouring an antecedent other than the object. 
Conclusion. Our results suggest that prosodic factors affect the ways that pronouns are interpreted with respect to participants in the discourse. Thus, it is essential that tasks devised to assess performance on pronoun interpretation include the means to assess prosody and not just the written language.

(1) a. Target sentence: $\quad$ Lorenzo ha scritto a Roberto quand $\varnothing /$ lui si è trasferito a Torino.

'Lorenzo wrote to Roberto when (he) moved to Turin.'

b. Comment:

Subject: $\quad$ È Lorenzo che si è trasferito a Torino.

'It is Lorenzo who moved to Turin.'

Object: $\quad$ È Roberto che si è trasferito a Torino.

'It is Roberto who moved to Turin.'

External: $\quad$ È una persona diversa da Lorenzo e Roberto che si è trasferito a Torino.

'It is a person other than Lorenzo or Roberto who moved to Turin.'

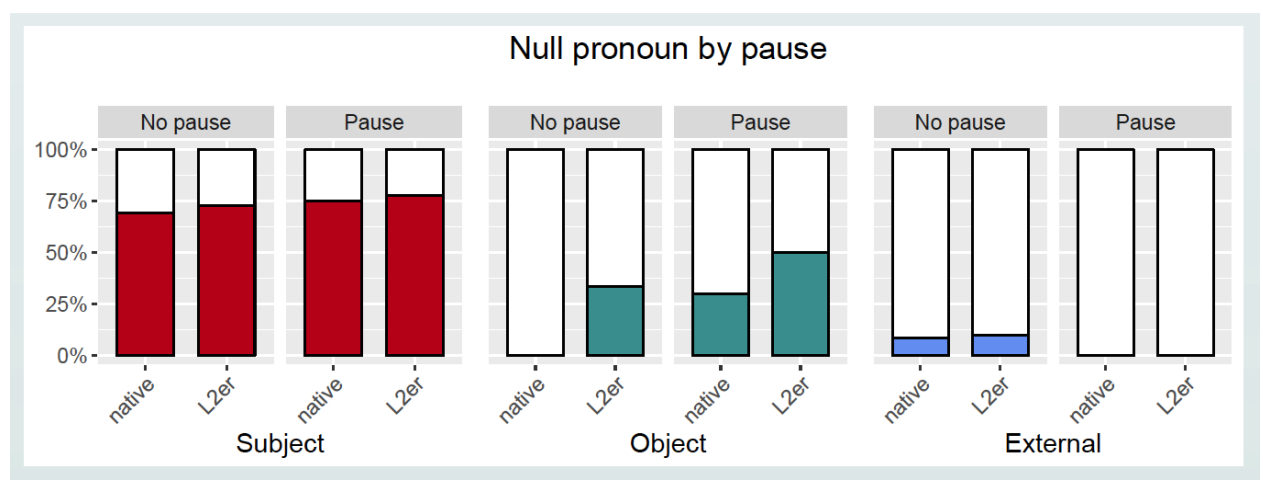

Figure 1. Subject/Object/External responses for null pronouns by pause.

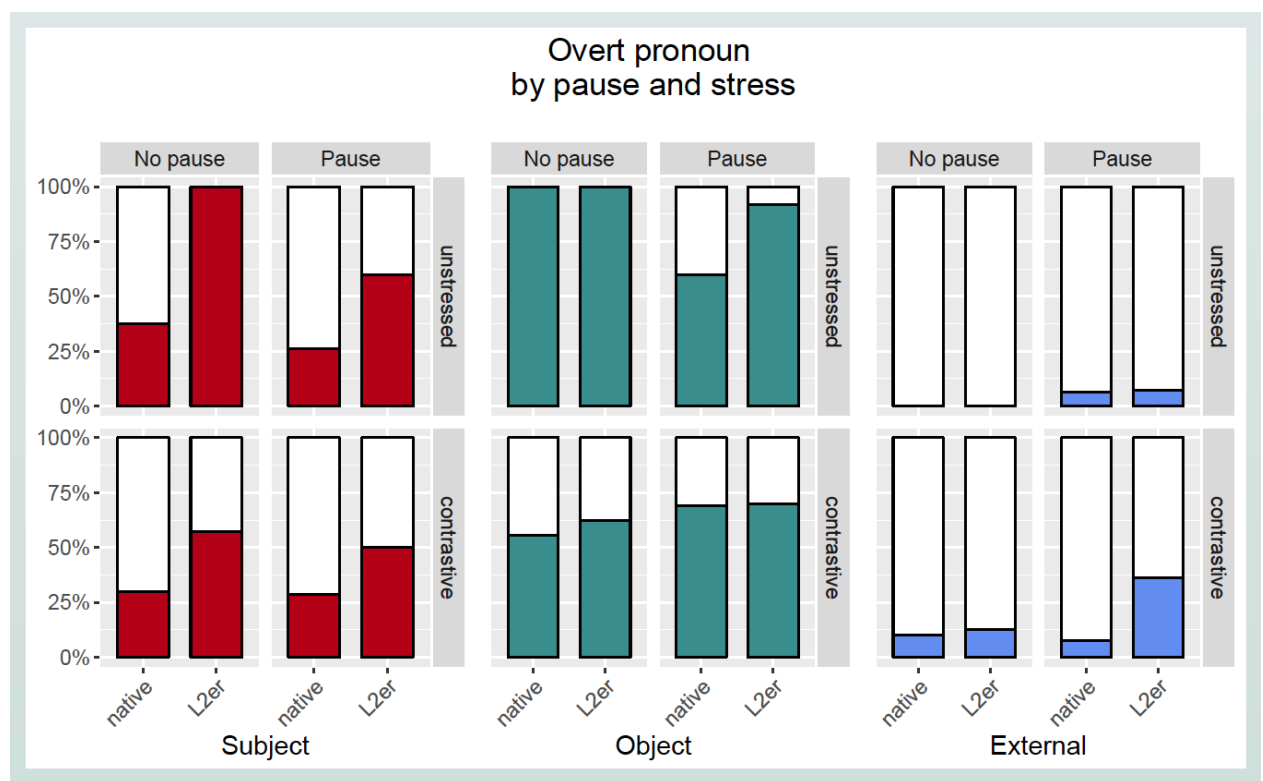

Figure 2. Subject/Object/External responses for overt pronouns by pause and stress.

Note: Colours in figures indicate agreement with comment; white parts indicate disagreement. 


\section{References}

Belletti, A., Bennati, E., \& Sorace A. (2007). Theoretical and developmental issues in the syntax of subjects: Evidence from near-native Italian. Natural Language and Linguistic Theory 25: 657-689.

Carminati, M. (2002). The processing of Italian subject pronouns. PhD. dissertation, University of Massachusetts, Amherst.

Sorace, A. \& Filiaci, F. (2006). Anaphora resolution in near-native speakers of Italian. Second Language Research 22: 339-368.

Correspondence Authors - Heather Goad, heather.goad@mcgill.ca; Lydia White, lydia.white@ mcgill.ca 